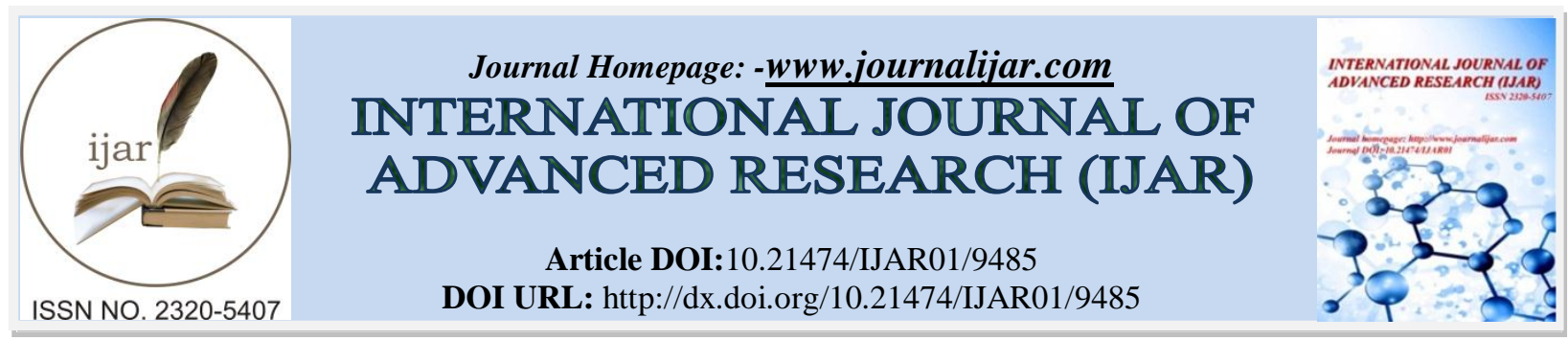

RESEARCH ARTICLE

\title{
INVOLVEMENT OF SCHISTOSOMA HAEMATOBIUM IN HEPATIC INJURY IN PAPA VILLAGE, SOUTHWEST NIGERIA.
}

Oladapo A. A. ${ }^{1}$, Ogundiran S. $\mathbf{M}^{2}$ and Oseni B. S. A ${ }^{3}$.

1. William Newton Memorial Hospital, Winfield, Kansas 67156 USA.

2. Coffey County Hospital Laboratory, Burlington, Kansas 66839 USA.

3. Department of biomedical sciences, Ladoke Akintola University of technology, Ogbomosho,Nigeria.

\section{Manuscript Info}

\section{Manuscript History}

Received: 05 June 2019

Final Accepted: 07 July 2019

Published: August 2019

Key words:-

Schistosoma haematobium, Total

Protein (TP), Albumin, Erythrocyte Sedimentation Rate (ESR), Prothrombin Time (PT), and Partial Thromboplastin Time with Kaolin (PTTK).

\section{Abstract}

Neglected tropical disease such as urinary schistosomiasis have had devastating effects on the renal system, which has been extensively studied but its effect on the liver and liver proteins still remain largely unknown despite schistosoma haematobium spending a major part of its lifecycle in the veins surrounding the liver and hepatic portal system. In this experiment, we assessed the prevalence and effect of schistosoma haematobium on the human liver among the dwellers of Papa village, Osun state Nigeria. We utilize 60 test samples consisting mainly of the dwellers from Papa village and 60 control samples collected from Osogbo urban city in Osun state Nigeria, which were screened for schistosoma haematobium eggs to establish prevalence of the parasite. Also, both the test sample and control sample were subjected to coagulation and biochemical analysis to ascertain the severity of schistosoma haematobium on the liver. The result showed the presence of an average of 440 eggs of schistosoma haematobium per $10 \mathrm{mls}$ in the test population and no schistosoma haematobium egg in the control population. There was a significant difference in the value of total protein, globulin, albumin, erythrocyte sedimentation rate, prothrombin time and partial thromboplastin time with kaolin when the test population was compared to the control population. These blood parameters were indicative of the severity of schistosoma haematobium infection on the liver. Combination strategies such as Intensive health education, vector control and early treatment should be recommended in combating the presence of schistosoma haematobium and prevent egg migration in visceral organs of the body, including the liver.

Copy Right, IJAR, 2019,. All rights reserved.

\section{Introduction:-}

Urinary schistosomiasis is caused by Schistosoma haematobium, which is a dimorphic parasitic trematode that reside in human bloodstream resulting in intravascular debilitating disease transmitted by a freshwater snail (Steinmann et al., 2006; Gryseels et al., 2006). Urinary schistosomiasis can be considered as an occupational disease, mostly rampant in rural communities that are transmitted through agricultural and water-related activities 
such as swimming, fishing, recreation, bathing and cloth washing (WHO, 2014; Cowper, 1963). Urban schistosomiasis is gradually becoming an increasing problem in many countries but the disease is still largely an infection found in rural settings (Mott et al., 1990). Schistosoma haematobium endemicity has been associated with 53 countries of the world, with majority of the locations in the African continent and the Middle-East (Chitsulo et al., 2000). In sub-sahara Africa, schistosomiasis is the second most important vector-borne disease posing serious public health challenge as indicated by the World health organization (WHO, 2016). The distribution of Schistosoma haematobium can vary across population and regions within a country whose prevalence has been established, as it is highly dependent on human-water related activities, reservoir host snail population, irrigation system, migration and population growth (Gryseels and Nkulikyinka, 1988; Gryseels et al., 2006; McManus and Loukas, 2008).

The transmission cycle of schistosoma haematobium involve the release of eggs in urine of definitive host, the excreted eggs hatch when in-contact with water releasing the miracidium to locate a suitable intermediate freshwater snail host (Gryseels and De Vlas, 1996). Asexual multiplication of the miracidium occurs in the snail resulting in a large number of multiplying larvae, with each producing cercariae (an infective larvae with bifurcated tail that penetrate the skin) (Oyinloye et al., 2014; Gryseels and De Vlas, 1996). The cercariae transform into a schistosomulum after penetrating the human host skin and losing its tail, with subsequent migration to the hepatic portal system where the adult worm mature in pairs in the surrounding veins of the liver, urinary bladder and intestines (Oyinloye et al., 2014; Gryseels and De Vlas, 1996). In the surrounding veins, they produce eggs which are majorly eliminated in the urine of the human host to the surrounding and the cycle continues (Oyinloye et al., 2014). Schistosoma haematobium has been able to maintain this transmission cycle by the habitual sustenance of indiscriminate freshwater contamination with urine containing schistosome eggs, the presence of intermediate snail host and the contact of definitive human host with water-infested cercariae (Gryseels and De Vlas, 1996).

Presently, the severity of schistosoma haematobium infection are diagnose through clinical symptoms and complications such as renal failure, polyposis, urothelial cancer, bladder ulcer and multiple disorders resulting in mortality and morbidity (Smith and Christie, 1986; Vennervald, 2015; Ismail et al. 2013). Poor psychological, social and physical development especially in adolescent and children of school-going age are some resultant clinical manifestation of schistosoma haematobium (Anigbo and Nwaorgu, 1990). Also, reactive oxygen species has been observed in schistosoma haematobium infection as a result of the intense inflammation produced by the deposition of the parasite ova in the urinary bladder causing carcinogenic N-nitrosamine production and chronic bacterial infection (Zaghloul, 2012; Groeneveld et al., 1996). Despite the lack of vaccination against schistosoma haematobium, chemotherapeutic strategy using praziquantel has been the widely selected approach in combating the parasite (Gray, 2011).

High incidence of schistosoma haematobium re-occurrence and persistence transmission of the parasite has further increase its worldwide spread, despite world health organization's strategy at combating it which has made eradication near impossible. Also, quantifying the damages caused by the parasite, which has not been extended to the liver despite schistosoma haematobium spending a major part of its lifecycle in the veins surrounding the liver and hepatic portal system has made this study essential. In this experiment, we assessed the prevalence and resultant effect of schistosoma haematobium on the human liver among the dwellers of Papa village, Osun state Nigeria. Here, we hypothesized that schistosoma haematobium will prolonged coagulation factors and impact the biochemical analytes demonstrated in this experiment, which are useful markers to ascertain proper liver functioning.

\section{Materials and methods:- Description of study area}

This experiment was conducted in Papa village, Olorunda Local Government Area in Osun State, Nigeria which lies in the South Western part near the Atlantic Ocean. Papa village is a rural community with a population of 100 people made up mainly peasant fisherman and women. Papa village has no pipe borne water and the village dwellers depend mainly on streams and ponds for their drinking and water-related activities. Also, there are no proper toilet facilities, hence village dwellers defecate and urinate indiscriminately in the surrounding environments and water bodies. 


\section{Subjects and Consent}

This study was conducted in Papa village, Osun State Nigeria. Sixty people were randomly selected for both age and sex from the village to participate in this study. Ethical approval was sought and obtained from the Osun State Ministry of health Osogbo, Osun State Nigeria. The village head was extensively briefed on the significance of this study and consent was sought and obtained from the individuals that participated in this experiment.

\section{Sample Collection and Storage}

Labeled sterile universal sample bottles were used to collect terminal urine between 1100 hour and 1400 hour from the dwellers of Papa village between the ages of 5 years and 70 years. After urine collection, $10 \mathrm{mls}$ of the urine was preserved in 4 drops of commercial bleach. Also, $6 \mathrm{mls}$ of blood was collected from the anticubital veins of the dwellers of Papa village and $3 \mathrm{mls}$ transferred into a plain dry sample bottle which was allowed to clot, centrifuged and separated to harvest the serum. Another $3 \mathrm{mls}$ of the sample was collected into a sodium citrate anticoagulated bottle in a ratio 9:1 for coagulation studies. The separated serum was stored at $-20^{\circ} \mathrm{C}$ for biochemical analysis and the blood for coagulation studies was stored at $4^{0} \mathrm{C}$ until ready for analysis.

\section{Urine Analysis}

The $10 \mathrm{mls}$ of blench preserved urine samples were individually poured into a centrifuged tube and spurred for five minutes at $5000 \mathrm{rpm}$. The method employed for the estimation of Schistosoma haematobium eggs per individual was the revised sedimentation method. The supernatant was decanted and the sediment transferred into a well cleaned counting chamber with a $1 \mathrm{~cm}^{3}$ capacity for the determination of Schistosoma haematobium egg density. A tally counter was used to count the Schistosoma haematobium eggs as viewed under the microscope and the total number of eggs found in each individual $10 \mathrm{mls}$ of urine sample was recorded (Dazo and Biles, 1974). Also, samples with haematoria were noted before preservation.

\section{Biochemical and Coagulation Analysis}

The erythrocyte sedimentation rate of every individual blood sample was measured through a modified western gren method as demonstrated by Laffen et al., 2001. This method measures the rate at which red blood cell fall when whole blood is allow to stand vertically for a period of 1 hour. A modified biuret method was used to estimate the total protein of the individual blood samples collected for this experiment with the absorbance measured spectrophotometrically at $540 \mathrm{~nm}$ (Myron et al., 1999). Albumin was measured by bromocresol green method by determining the absorbance spectrophotometrically at $620 \mathrm{~nm}$ (Myron et al., 1999). Total Serum globulin level was calculated by the subtraction of serum albumin from the serum total protein (McPherson, 1984). Prothrombin time was determined by the manual tilt-tube method and the international normalized ratio (INR) was calculated to allow for the worldwide standardization of the result (Barbara et al., 2009). Proctor and Rappaport method was used to determine the partial thromboplastin time with kaolin in the plasma of each individual dwellers of Papa village (Barbara et al., 2001).

\section{Data and statistical analysis:}

In this study, Statistical Package for Social Sciences (SPSS) was used to analyse all in this study, and all the collected data for statistical correlation. All the measured data in the study are indicated with respect to the mean \pm standard error of the mean (SEM). The means of the groups were compared using one-way ANOVA was used to compare the means of the test and control groups, while t-test examine the significant difference between them $(\mathrm{P}<0.05)$.

\section{Result:-}

In this experiment, 60 dwellers of Papa village, Osun state Nigeria and 60 dwellers from Osogbo urban city area of Osun state, Nigeria were used for the test population and control population respectively. Both the test population and control population were subjected to biochemical and coagulation analysis. The biochemical parameters used in this study are total protein, albumin and globulin while the coagulation parameters are prothrombin time (PT), partial thromboplastin time with kaolin (PTTK) and erythrocyte sedimentation rate (ESR).

The experiment showed an average of 440 eggs of schistosoma haematobium per $10 \mathrm{mls}$ of urine were observed in the test population, which consisted mainly of the dwellers of Papa village and 0 eggs of schistosoma haematobium per $10 \mathrm{mls}$ of urine were seen in the control population. 
Table 1 showed the overview of all the results of the biochemical analytes and coagulation studies as quantified in mean and standard error of the mean. In Figure 1, the serum total protein level was significantly higher in the test population $(8.36 \pm 0.78) \mathrm{g} / \mathrm{dl}$ when compared to the control population $(6.67 \pm 0.24) \mathrm{g} / \mathrm{dl}$. Also, there was a significant decrease in serum albumin level in the test population $(3.43 \pm 0.41) \mathrm{g} / \mathrm{dl}$ in comparison to the control population $(4.14 \pm 0.20) \mathrm{g} / \mathrm{dl}$. A significant increase was observed in the level of serum globulin in the test population $(4.86 \pm 0.96) \mathrm{g} / \mathrm{dl}$ when compared with the control population $(2.53 \pm 0.37) \mathrm{g} / \mathrm{dl}$.

Figure 2 revealed that the erythrocyte sedimentation rate was significantly increased in the test population $(18.13 \pm$ 5.06) $\mathrm{mm} / \mathrm{hr}$ as compared to the control population $(3.73 \pm 0.64) \mathrm{mm} / \mathrm{hr}$. In figure 3 , the test population $(3.92 \pm$ 1.77) has an INR that was significantly higher than the control population $(1.02 \pm 0.15)$. Figure 4 showed that there was a significant increase in the level of partial thromboplastin time with kaolin in the test population (65.0 \pm 1.60$)$ seconds when compared to the control population $(38.0 \pm 0.21)$ seconds.

\begin{tabular}{|l|l|l|}
\hline PARAMETERS & CONTROL $(\mathrm{N}=60)$ & TEST $(\mathrm{N}=60)$ \\
\hline TOTAL PROTEIN $(\mathrm{g} / \mathrm{dl})$ & $6.67 \pm 0.24$ & $8.36 \pm 0.78^{*}$ \\
\hline ALBUMIN $(\mathrm{g} / \mathrm{dl})$ & $4.14 \pm 0.20$ & $3.43 \pm 0.41^{*}$ \\
\hline GLOBULIN $(\mathrm{g} / \mathrm{dl})$ & $2.53 \pm 0.37$ & $4.86 \pm 0.96^{*}$ \\
\hline ESR $(\mathrm{mm} / \mathrm{hr})$ & $3.73 \pm 0.64$ & $18.13 \pm 5.06^{*}$ \\
\hline PT $(\mathrm{INR})$ & $1.02 \pm 0.15$ & $3.92 \pm 1.77^{*}$ \\
\hline PTTK $($ seconds) & $38.0 \pm 0.21$ & $65.0 \pm 1.60$ \\
\hline
\end{tabular}

Table 1:-Shows the mean and standard error of various coagulation factors and biochemical analytes between the test population and control. The test population are the dwellers of Papa village while the control population are dwellers of Osogbo urban city, Osun state Nigeria.

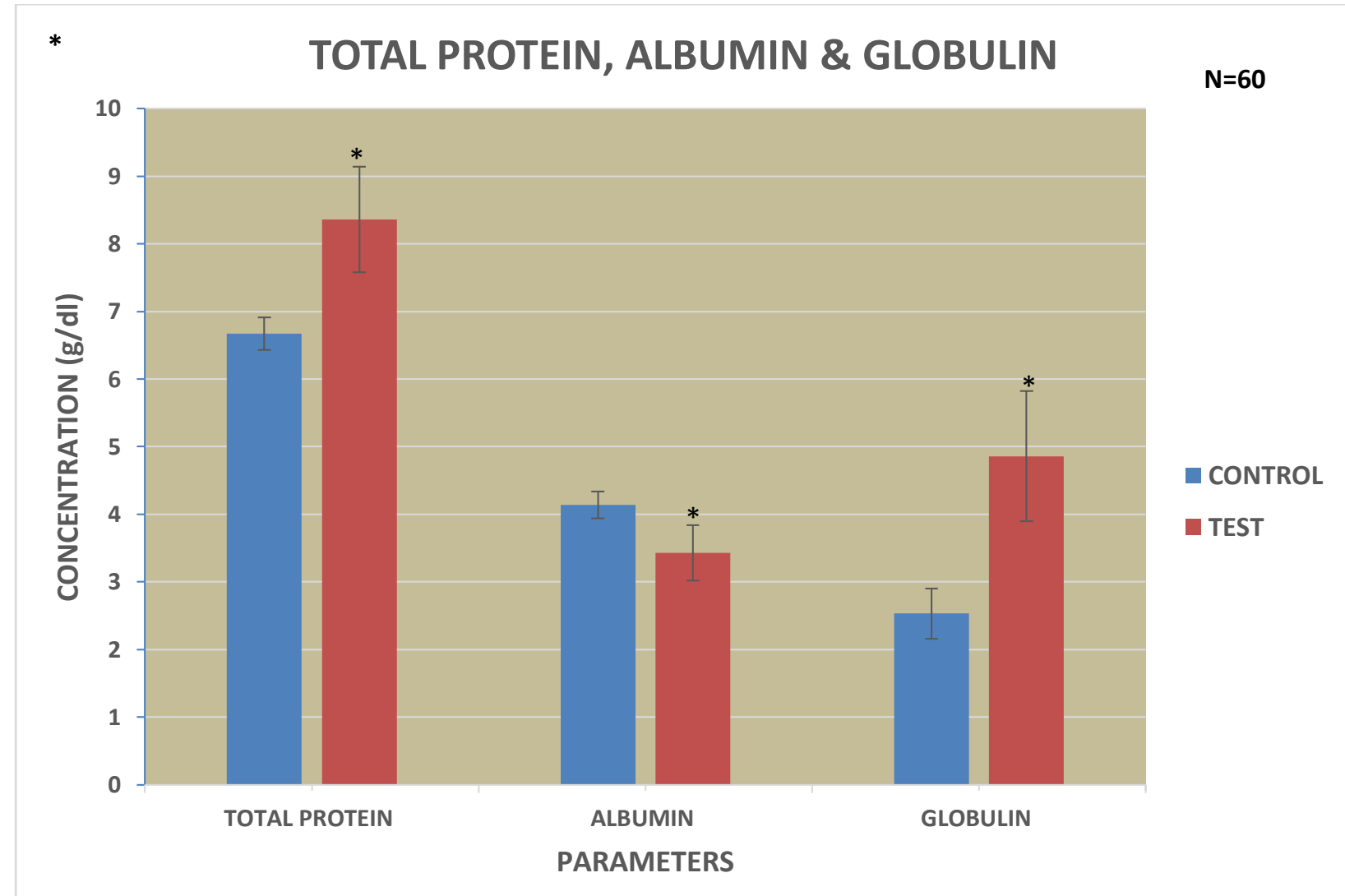

Figure 1: The Effect of schistosoma haematobium on biochemical analytes. Data are shown as mean \pm SEM of Total protein, albumin and globulin. * was used to represent the level of significance at $\mathrm{P}<0.05$ when test population was compared to the control population. $\mathrm{N}$ represents the total number of individuals in each population group. 


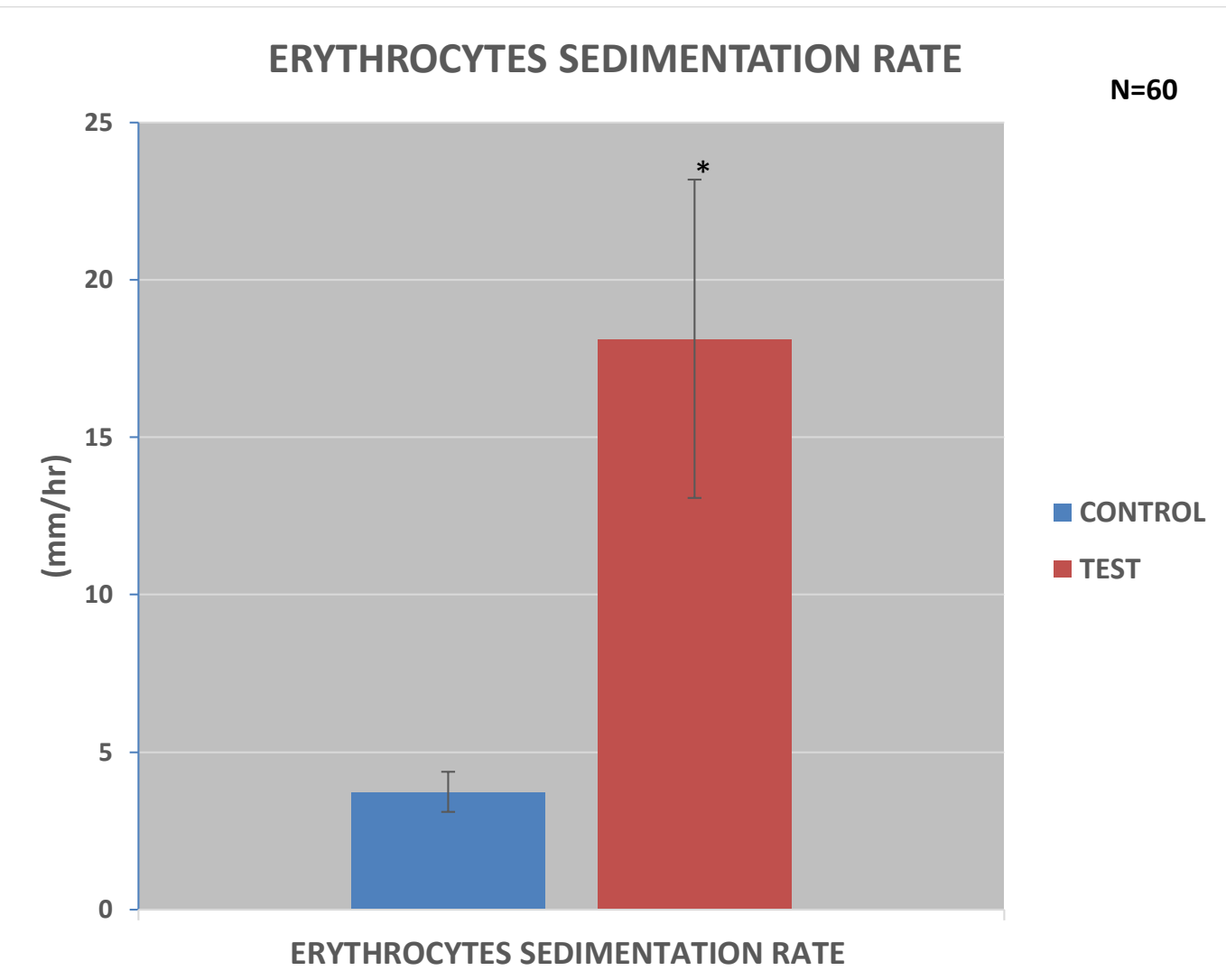

Figure 2: The Effect of schistosoma haematobium on erythrocyte sedimentation rate (ESR). Data are shown as mean \pm SEM of ESR. * was used to represent the level of significance at $\mathrm{P}<0.05$ when test population was compared to the control population. $\mathrm{N}$ represents the total number of individuals in each population group.

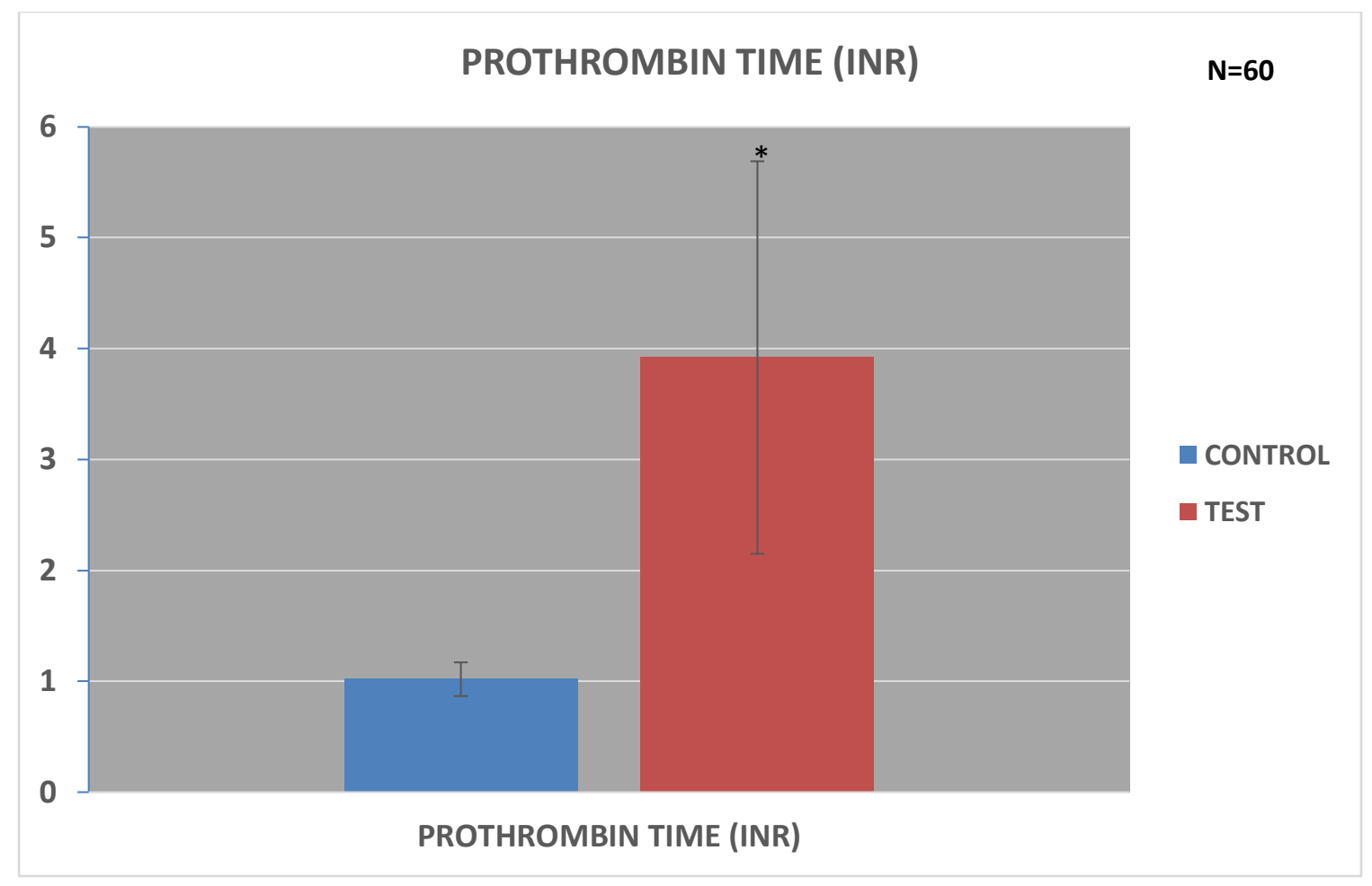


Figure 3: The Effect of schistosoma haematobium on coagulation studies. Data are shown as mean \pm SEM of prothrombin time. * was used to represent the level of significance at $\mathrm{P}<0.05$ when test population was compared to the control population. $\mathrm{N}$ represents the total number of individuals in each population group.

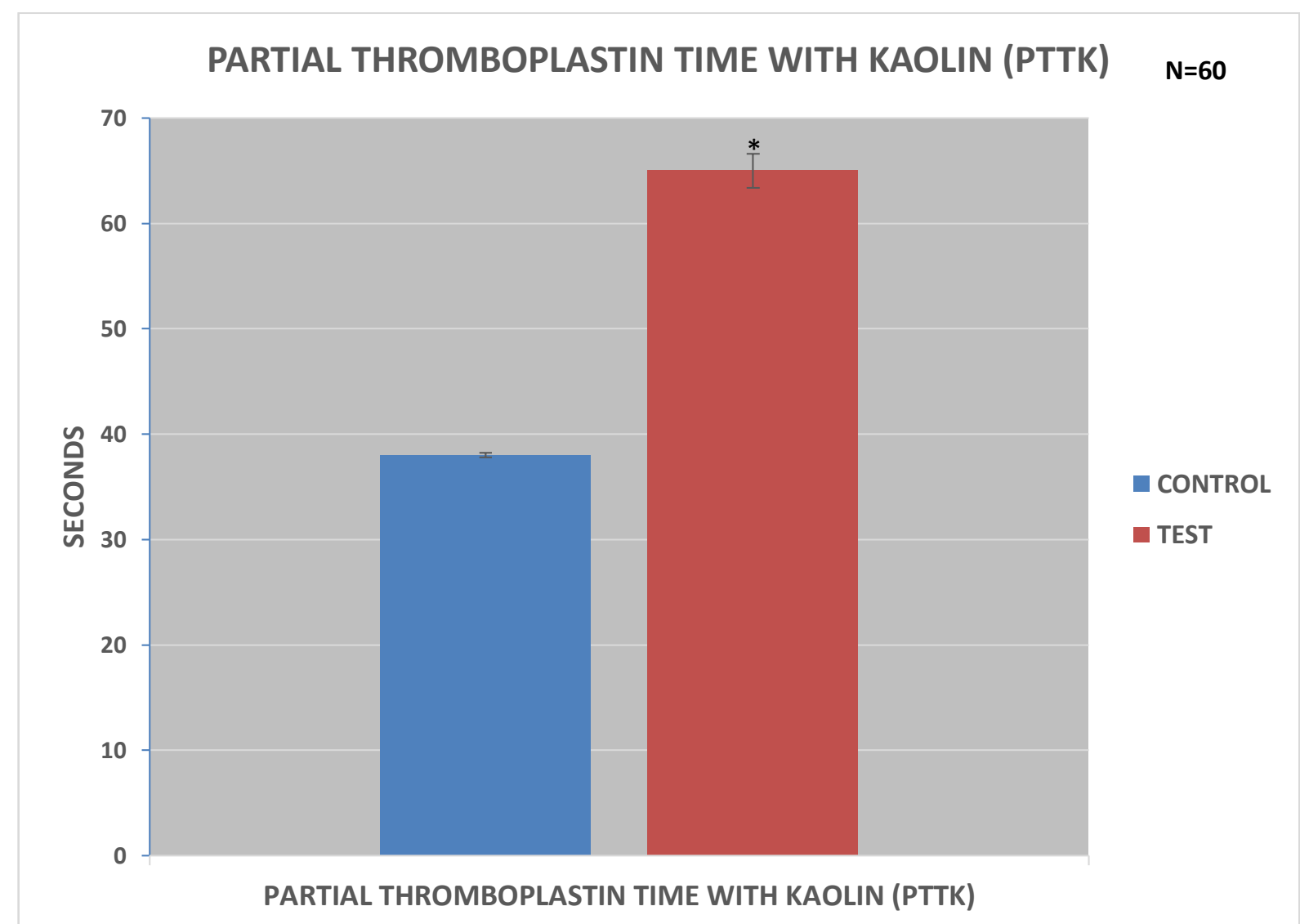

Figure 4: The Effect of schistosoma haematobium on coagulation studies. Data are shown as mean \pm SEM of partial thromboplastin time with kaolin. * was used to represent the level of significance at $\mathrm{P}<0.05$ when test population was compared to the control population. $\mathrm{N}$ represents the total number of individuals in each population group.

\section{Discussion:-}

In our study, we demonstrated the prevalence and severity of schistosoma haematobium infection on the liver of the dwellers of a riverine community called Papa village in Osun state, Nigeria. Urinary schistosomiasis has been implicated as a major health problem in the rural communities of African and Middle Eastern part of the world (WHO, 2016). In our study, we observed a high schistosome egg count of 440 per $10 \mathrm{ml}$ of urine in each Papa village dwellers that was involved in this experiment which indicated endemicity of urinary schistosomiasis in this area. The presence of the high egg count of schistosoma haematobium in this area can be as a result of poor living condition, ignorance as most dwellers are either uneducated or semi-educated individuals and inadequate sanitation. This study was supported by Badmos et al., 2007 who examine 1000 cases of histological section of appendicitis and observed $26.0 \%$ prevalence of schistosoma haematobium. Also, the endemicity of the disease in many rural areas has been attributed to poor sanitary condition, scarcity of relevant information, environmental and personal hygiene in-combination with water-related activities in infected snail river or Pond (Anto et al., 2013).

In our study, serum albumin level was significantly reduced in the test populations, which are the dwellers of Papa village when compared to the control populations as observed in figure 1. This reduction in the schistosoma haematobium infected population can be associated with blood loss in terminal urine along with albumin, liver inflammation and dysfunction as well as poor nutritional status. The result of this study was supported by Elagba et al., 2006 that proposed high protein loss as a result of urinary protein excretion and heavy infection to be responsible for the low serum albumin level observed in their study. Also, serum total protein and globulin level were 
significantly increased in test population containing the serum obtained from Papa village dwellers when compared to the control population as seen in figure 1 . The increase in the serum total protein despite reduced albumin with an elevated globulin could be due to the positive immune response of the infected population to the schistosoma haematobium infection by the production of immunoglobulin which was supported by Elagba et al., 2006. Elagba et al., 2006 confirmed that immunological reaction, immunoglobulin production and infection intensity is responsible for the elevated serum total protein and globulin in their work on schistosoma hematobium morbidity in Sudan school students.

In figure 3 and 4, we examine two coagulation studies to determine the liver function; prothrombin time and partial thromboplastin time with kaolin. This study demonstrated a significantly prolonged prothrombin time and partial thromboplastin time with kaolin in the schistosoma haematobium infected population when compared to the control population. The result can be attributed to the function of the liver being compromised with regards to the production of coagulation proteins or interference at various stages in coagulation pathway by the schistosoma haematobium. This result was supported by Mebius et al., 2013 report that schistosoma haematobium implement several mechanism to actively manipulate vascular tone, inhibit blood coagulation cascade and exploit host haemostasis regulation. Also DeWitt and Warren in 1959 suggest that the penetration of schistosome eggs in large of the liver portal canals result in portal blood flow obstruction and granulomatous reaction.

\section{Conclusion:-}

This study confirmed the prevalence of schistosoma haematobium in a rural setting such as Papa village in Osun state, Nigeria. We were also able to enumerate some diagnostic model that was suggestive of the role of schistosoma haematobium in liver injury and abnormal function. We recommend that extended hepatic function test and liver biopsy to be done to further establish the effect of schistosoma haematobium on the liver.

\section{Conflict Of Interest}

No conflict of interest was declared by the authors

\section{Refernces:-}

1. Anigbo, E. U. and Nwaorgu, O. C. (1994). Urinary Schistosomiasis in two family populations, using school children as tracer. Nig. J. Parasitol., 9(11): 41-46.

2. Anto, F., Asoala, V., Adjuik, M. A., Anyorigiya, T., Oduro, A. R., Akazili, J., Akweongo, P., Ayivor, P. K., Bimi, L. and Hodgson, A. V. O. (2013). Water Contact Activities and Prevalence of Schistosomiasis Infection among School-age Children in Communities along an Irrigation Scheme in Rural Northern Ghana. J. Bacteriol. Parasitol., 4: 177.

3. Badmos, K. B., Komolafe, A. O. and Rotimi, O. (2007). Schistosomiasis presenting as acute appendicitis. East Afr. Med. J., 83: 528-532.

4. Chitsulo, L., Engels, D., Montresur, A. and Saviol,i L. (2000). The global status of schistosomiasis and its control. Acta Trop., 77: 41-51.

5. Cowper, S. G. (1963). Schistosomiasis in Nigeria. Ann. Trop. Med. Parasitol., 57:307-332.

6. DeWitt, W. B. and Warren, K. S. (1959). Hepato-Splenic Schistosomiasis in Mice. Am. J. Trop. Med. Hyg., 8(4): $440-446$.

7. Elagba, H. A., Mohamed, E. and Hikmat, I. (2006). Haematological and Biochemical morbidity of Schistosoma Haematobium in school children in Sudan. Sultan Qaboos Univ. Med. J., 6(2): 59-64.

8. Gray, D. J., Ross, A. G., Li, Y. and McManus, D. P. (2011). Diagnosis and management of schistosomiasis. Br. Med. J., 342:d2651.

9. Groeneveld, A. E., Marszalek, W. W. and Heyns, C. F. (1996). Bladder cancer in various population groups in the greater Durban area of KwaZulu-Natal: South Africa. Br. J. Urol., 78:205-8.

10. Gryseels, B. and DeVlas, S. J. (1996). Worm burdens in schistosome infections. Parasitology Today, 12:115119.

11. Gryseels, B. and Nkulikyinka, L. (1988). The distribution of Schistosoma mansoni in the Rusizi plain (Burundi). Ann. Trop. Med. Parasitol., 82: 581-590.

12. Gryseels, B., Polman, K., Clerinx, J. and Kestens, L. (2006). Human schistosomiasis. Lancet, 368: 1106-1118.

13. Ismail, K., Ahmed, S. and Mohamed, S. (2013). Urologic complications of genitourinary schistosomiasis. World J. Urol., 30(1): 31-8. 
14. McManus, D. P. and Loukas, A. (2008). Current status of vaccines for schistosomiasis. Clin. Microbiol. Rev., 21: 225-242.

15. McPherson, R. A. (1984). Specific proteins. In: Clinical diagnosis and management, Henry, J. B. ed. Philadelphia: W. B. Saunders, 204-14.

16. Mebius, M. M., van Genderen, P. J. J., Urbanus, R. T., Tielens, A. G. M., de Groot, P. G., van Hellemond, J. J. (2013). Interference with the Host Haemostatic System by Schistosomes. PLoS Pathog., 9: 12 e1003781.

17. Mott, K. E., Desjeux, P. and Moncayo, A. (1990). Parasitic diseases and urban development. Bull. World Health Organ., 68(6): 691-698.

18. Oyinloye, B., Adenowo, F., Gxaba, N. and Kappo, A. (2014). The promise of antimicrobial peptides for treatment of human schistosomiasis. Curr. Drug Targets, 15: 852-9.

19. Smith, J. H. and Christie, J. D. (1986). The pathobiology of schistosoma haematobiuminfection in humans. Hum. Pathol., 17(4): 333-345.

20. Steinmann, P., Keiser, J., Bos, R., Tanner, M. and Utzinger, J. (2006). Schistosomiasis and water resources development: systematic review, meta-analysis, and estimates of people at risk. Lancet Infect. Dis., 6: 411-425.

21. Vennervald, B. J. (2015) Epidemiology and Mechanism of Carcinogenesis of Schistosomiasis. In: Droz, J. P., Carme, B., Couppié, P., Nacher, M. and Thiéblemont, C. (eds) Tropical Hemato-Oncology. Springer, Cham.

22. WHO Schistosomiasis fact sheets (2016) viewed at www.who.int/mediacentre/factsheets/fs115/en/. Accessed 05.05.19.

23. WHO schistosomiasis fact sheet. (2014). http:// www.who.int/mediacentre/factsheets. accessed 05.05.19.

24. Zaghloul, M. S. (2012). Bladder cancer and schistosomiasis. J. Egypt. Natl. Canc. Inst., 24: 151-159. 